The Limited Informativeness of Meta-Analyses of Media Effects

\author{
Patti M. Valkenburg \\ University of Amsterdam
}

Please cite this article as: Valkenburg, P. M. (2016). The limited informativeness of meta-analyses of media effects. Perspectives in Psychological Science, 10, 5, 680-682. doi: 10.1177/1745691615592237 


\begin{abstract}
In this issue of PPS, Christopher Ferguson reports on a meta-analysis that examined the relationship between children's video game use and several outcome variables, including aggression and attention deficit symptoms. In this commentary, I compare Ferguson's nonsignificant effects sizes with earlier meta-analyses on the same topics that yielded larger, significant effect sizes. I argue that Ferguson's choice for partial effects sizes is unjustified on both methodological and theoretical grounds. Following this, I make a plea for a more constructive debate on the effects of violent video games on children and adolescents. Until now, this debate has been dominated by two camps with diametrically opposed views on the effects of violent media on children. However, even the earliest media effects studies tell us that children can react quite differently and sometimes even opposite to the same media content. Thus, if researchers truly want to understand how media affect children, rather than fight for the presence or absence of effects, they need to adopt a perspective that takes differential susceptibility to media effects more seriously.
\end{abstract}




\section{The Limited Informativeness of Meta-Analyses of Media Effects}

"That the movies exert an influence there can be no doubt. But it is our opinion that this influence is specific for a given child and a given movie. The same picture may influence different children in distinctly opposite directions. Thus in a general survey such as we have made, the net effect appears small."

W.W. Charters (1933, p. 16).

This 1933 quote reflects one of the main conclusions of the well-known Payne Fund studies, the first empirical studies on the effects of media use (motion pictures) on youth. Through twelve triangulated studies, the Payne Fund researchers confirmed that children differ greatly in their susceptibility to media effects. At that time, the Payne Fund conclusion was quite remarkable. Behaviorism was the dominant school of thought and individual differences in responses to environmental cues were typically ignored in the social and behavioral sciences. In the decades that followed, several other landmark studies yielded findings in line with the Payne Fund Studies. For example, in 1961 Schramm, Lyle and Parker found that: "For some children under some conditions some television is harmful. For other children under the same conditions or for the same children under other conditions it may be beneficial. For most children under most conditions, most television is probably neither particularly harmful nor particularly beneficial.” (p. 3).

Since these early studies, researchers have continued to evaluate the extent to which media affect their users. This growing body of research has resulted in an upsurge in metaanalyses on the effects of different types of media (television, movies, computer games, advertising, etc.). This increase in meta-analyses is important for the field of media effects, as they help us integrate the findings in this vastly growing literature. Unfortunately, however, meta-analyses can suffer from the same shortcomings as the empirical studies that are included within them.

\section{Shortcomings of Meta-Analyses}

Meta-analyses may suffer from at least two shortcomings. First they are only as good as the studies that they attempt to integrate, and they are not (or hardly) able to compensate for omissions in the empirical literature. If, for example, the empirical studies included in the meta-analysis fail to include dispositional (e.g., temperament), developmental, or social (e.g., 
family environment) factors known to interact with media effects, meta-analyses based on these studies cannot make up for these omissions. Second, just like empirical studies, metaanalytic results are prone to the subjective choices and emphases of the researchers. Let me illustrate this point by comparing the part of Ferguson's meta-analysis on computer games and attention deficit symptoms with our meta-analysis on the same topic that was recently published (Nikkelen, Valkenburg, Huizinga, \& Bushman, 2014).

\section{Comparing Results from Two Similar Meta-analyses}

Ferguson's meta-analysis yielded a zero-order correlation of $r=.10$ between playing computer games and attention deficit symptoms. Although his meta-analysis is based on fewer studies than ours, Ferguson's zero-order relationship does not diverge much from ours $(r=.12)$. The main difference between the two meta-analyses is that Ferguson strongly emphasized (in abstract and text) the partial correlation of $r=.03$ between media use and attention deficit symptoms, whereas ours reported the zero-order correlation. Ferguson's partial correlation is based on six studies that together included a hodgepodge of control variables. In our study, we presented the raw correlations, because to the best of my knowledge, the CMA software (which both of us used) is not supposed to be used to metaanalyze partial correlations.

However, there are also theoretical reasons for our choice to present raw correlations. Although several empirical studies on the relationship between media use and attention deficit symptoms have controlled for variables such as gender, age, and parenting, doing so may easily obscure the relationship between media use and attention deficit problems. For example, while Ferguson's meta-analysis showed that controlling for such variables indeed lowered the statistical relationship between media use and attention deficit problems (from $r$ $=.10$ to $r=.03$ ), our meta-analysis (in which we treated gender as a moderator instead of a control) showed that the relationship between media use and attention deficit problems is stronger for boys than for girls (Nikkelen et al., 2014). Other recent research similarly has shown that boys, younger children, and children in violent families are more susceptible to violent media than their counterparts (Fikkers et al., 2013), which further points to the need to treat such individual-difference variables as moderators rather than controls.

\section{Typical Effects Sizes in Media Effects Research}

What strikes me most in Ferguson's publication is his seeming determination to 'prove' that computer games do not have any effects. This is not only the case in this publication but in his other publications as well. Ferguson (and coauthors) consistently reports lower effect 
sizes in their meta-analyses than other research groups. My observation has recently been confirmed in a meta-analysis by Greitemeyer and Mügge (2014) in which the authors showed that the meta-analytic effect sizes of Ferguson and colleagues are significantly lower than those found in other meta-analyses on the effects of media violence.

Meta-analyses of media effects typically yield small to modest effects sizes between $r=$ .10 and $r=.20$ (with some outliers in two directions; see Valkenburg \& Peter, 2013b, for a review). These effects sizes generally do not differ from the effect sizes that are found in many other academic disciplines. For example, meta-analyses on the effects of parenting strategies typically also yield only modest effect sizes (Valkenburg \& Peter, 2013b). However, unlike other academic disciplines, in the media-effects discipline (particularly in research of media violence effects), the interpretation of results seems to vary widely. Some researchers, like Ferguson, consider statistically small media effects as unimportant or negligible. Other researchers, including myself, believe that we have to take such effects seriously. Small statistical effects may imply individual differences in susceptibility to these effects. For example, most children are probably not or hardly influenced by media violence. But a small minority might be especially vulnerable to such effects. For these children, exposure to media violence may have intense and long-lasting consequences (Pearce \& Field, in press).

\section{A Plea for a More Constructive Debate}

What concerns me about the debate between Ferguson and other American mediaviolence researchers is the tone and the ad hominem arguments that they use. Criticisms and arguments are at the core of academia, and the best researchers are usually those who are sensitive to criticisms. However, the debate between these researchers is far beyond a constructive academic debate. It hinders, rather than promotes, the progress of our field. Each of the two 'camps' keep repeating their arguments, and come up with new 'proof' to support their stance and settle the dispute. What they fail to recognize is that both extremes of the debate are untenable. In fact, the notion of conditional media effects - that effects do not equally hold for all children - is now so common that it has become one of the most important paradigms of modern media effects research (Valkenburg \& Peter, 2013a).

Meta-analyses that yield small to moderate statistical effects sizes are of course informative, but not informative enough, at least when these effect sizes are based on large and heterogeneous groups of children. In such groups, effect sizes may be diluted across too many different children, who can, as observed more than 80 years ago in the Payne Fund 
studies, react to media content in very distinct ways. In my view, there are many more important questions to answer in the field of media effects. For example, which children are particularly susceptible to negative media effects? And why are most children not or hardly susceptible? Is this due to temperament, to a more protective social environment, or to both? And, are the children who are vulnerable to negative effects of media also more susceptible to positive media effects?

Personalized or differential susceptibility approaches are gaining prominence in ever more academic disciplines. In the medical sciences, personalized medicine is rapidly gaining importance. In the classroom, personalized learning has received renewed attention due to the rapid developments in communication technology. In developmental psychology, the dandelion-orchid hypothesis takes root, which states that the majority of children are like dandelions that thrive in both positive and negative environments. A small group of children are like orchids; they need an encouraging environment, and if they lack such an environment, they wilt or fade (Boyce \& Ellis, 2005; Piotrowski \& Valkenburg, in press).

Our differential susceptibility model of media effects (Valkenburg \& Peter, 2013a) argues that children - in part - shape their own media effects, for better and for worse. Media effects are the result of a complex and intertwined set of dispositional, developmental, and social influences. If we truly want to understand which children are susceptible to certain media effects, and equally important, which children are not, the field of media effects needs to move away from treating meta-analytic work amongst heterogeneous groups as the gold standard and instead privilege more nuanced approaches, which recognize the criticality of individual differences in susceptibility to media effects. 


\section{References}

Boyce, W. T., \& Ellis, B. J. (2005). Biological sensitivity to context: I. An evolutionarydevelopmental theory of the origins and functions of stress reactivity. Development and Psychopathology, 17, 183-187.

Charters, W. W. (1933). Motion pictures and youth: A summary. New York: Macmillan.

Fikkers, K.M., Piotrowski, J.T., Weeda, W.D., Vossen, H.G.M., \& Valkenburg, P.M. (2013). Double dose: High family conflict enhances the effect of media violence exposure on ado-lescents' aggression. Societies, 3, 280-292.

Greitemeyer, T., \& Mügge, D. O. (2014). Video games do affect social outcomes A metaanalytic review of the effects of violent and prosocial video game play. Personality and Social Psychology Bulletin, 40, 578-589.

Nikkelen, S. W. C., Valkenburg, P. M., Huizinga, M., \& Bushman, B. J. (2014). Media use and ADHD-related behaviors in children and adolescents: A meta-analysis. Developmental Psychology, 50, 2228-2241.

Pearce, K., \& Field, A. (in press). The impact of 'scary' TV and children's internalizing problems: A meta-analysis. Human Communication Research.

Piotrowski, J.T.\& Valkenburg, P.M. (in press). Finding orchids in a field of dandelions: Understanding children's differential susceptibility to media effects. American Behavioral Scientist.

Schramm, W., Lyle, J., \& Parker, E.B. (1961). Television in the lives of our children. Stanford, CA: Stanford University Press.

Valkenburg, P.M. \& Peter, J. (2013a). The differential susceptibility to media effects model. Journal of Communication, 63, 221-243.

Valkenburg, P.M. \& Peter, J. (2013b). Five challenges for the future of media-effects research. International Journal of Communication, 7, 197-215. 